\title{
Evaluation of the Mechanical Properties of Porous Thermoplastic Polyurethane Obtained by 3D Printing for Protective Gear
}

\author{
Hyojeong Lee, ${ }^{1}$ Ran-i Eom, ${ }^{2}$ and Yejin Lee ${ }^{3}{ }^{3}$ \\ ${ }^{1}$ Department of Fashion Design \& Merchandising, Kongju National University, Gongju-si, Chungcheongnam-do 32588, \\ Republic of Korea \\ ${ }^{2}$ Research Institute of Human Ecology, Chungnam National University, Daejeon 34134, Republic of Korea \\ ${ }^{3}$ Department of Clothing \& Textiles, Chungnam National University, Daejeon 34134, Republic of Korea \\ Correspondence should be addressed to Yejin Lee; yejin@cnu.ac.kr
}

Received 30 May 2019; Revised 3 September 2019; Accepted 4 October 2019; Published 7 December 2019

Academic Editor: MariaGabriella Santonicola

Copyright (c) 2019 Hyojeong Lee et al. This is an open access article distributed under the Creative Commons Attribution License, which permits unrestricted use, distribution, and reproduction in any medium, provided the original work is properly cited.

\begin{abstract}
Three-dimensional (3D) printing is an efficient and sustainable technology useful in various manufacturing fields. The aim of this study was to investigate the applicability of thermoplastic polyurethane (TPU) as a 3D printing material and the conditions related to the use of TPU as personal protective equipment. The tensile strength, shock absorption, and compressibility were evaluated for different infill and thickness conditions. An increase in the infill rate led to an increase in the tensile strength, regardless of the sample thickness. Similarly, the compression energy increased as the infill increased. Both the shock absorption and compression properties increased as the thickness decreased under identical infill conditions. The actual shock absorption test data were compared to the results of structural analyses, which confirmed the potential for predicting impact deformation through the analysis of the tensile characteristics and the basic properties of a 3D printed material.
\end{abstract}

\section{Introduction}

The advent of additive manufacturing (AM) has changed the face of product fabrication by supporting in-sourcing and promoting personal manufacturing businesses [1]. This has transformed not only the manufacturing industry but also the medical and distribution industries. Designing a solid product used to be a particularly time-consuming process, with many lengthy mock-ups, molding, and injection processes before a serviceable product could be made. However, AM allows complete parts to be manufactured from threedimensional (3D) models. The first stage in AM is typically the fabrication of the basic geometric shape, which is followed by a consolidation stage that enhances the fundamental properties of the intended material [2]. In addition, $3 \mathrm{D}$ printing has acted as an alternative process by which to reduce the time and cost needed to go through this process [3]. This technology is actively applied in a variety of industries (e.g., space science, medical, construction, and mechanical industries) for products such as art, toys, tools, and household items. Recent studies on RepRap devices have investigated the mechanical properties of printed parts for engineering applications [4]. In the fashion industry, 3D printing has been used to design everything from accessories to clothing [5]; however, only a few studies have analyzed its applicability in depth. New molding materials are continuously being developed but can largely be categorized as polyamide, polylactic acid (PLA), thermoplastic polyurethane (TPU), metal, ceramic, wood, and composite materials. Their initial shapes can be categorized as powder, solid filament, or liquid. However, 3D printed products often have different physical properties to the original polymer; hence, when particular functions are required from the product, a preceding examination is necessary to create the desired product through 3D printing [6]. Furthermore, as the physical and mechanical properties of the final product differ depending on the printing conditions regardless of the initial material or shape, verification is required $[7,8]$. The analysis of energy absorbing profiles for grading the density through the structure in a model of a 
lattice structure or a hexagonal array demonstrated that the wider range of compression energies exhibited a higher efficiency, and a greater magnitude of efficiency peaks was observed at the higher density layers [9-11]. However, studies on the recent development of the novel materials and applications in 3D printing are limited [12-14]. Many studies have dealt with density as a variable in the designer's modeling process. However, the infill conditions also need to be examined during $3 \mathrm{D}$ printing because the $3 \mathrm{D}$ printing user can adjust the density by varying the porosity with the infill condition. TPU is a common 3D printing material. Its linear polymer chains make it a straight line, with flexible and rigid chains connected through covalent bonding. Therefore, it displays high flexibility, elasticity, and shock resistance, like rubber, as well as thermoplasticity. Furthermore, it has excellent abrasion and tear resistance as well as high hardness [15-17]. In addition, TPU is easier to deform than PLA owing to its high elasticity [18]. Other researchers have applied TPU to golf or other functional shoes [19], as well as to baggage or flooring material because of its properties [20]. Attempts to join textile fabrics and 3D polymer filaments have revealed that TPU exhibits the best adhesion to fabrics [21]. In this study, we combined the rapid advance of 3D printing and TPU and confirmed their applicability for the production of hard shell personal protective equipment.

Currently, sports or industrial protective equipment that protect the hip joints, knees, elbows, and shin of the human body from shock damage mostly comprise hard shells with a soft interior. These are usually reinforced plastic and polyurethane foam, respectively. The reinforced plastic used in hard shells is strong, light, and durable but not flexible; thus, it does not respond well to body movement. This discomfort during movement is exacerbated when the product is ill-fitting. Therefore, substituting the hard shell with TPU, which is flexible and can protect from shock, is expected to create greater adherence and comfort during movement. It will also contribute to future part customization because TPU is easily combined with technologies such as 3D scanners, printers, and modeling, among others.

The ultimate purpose of this study was to investigate TPU's applicability for personal protective equipment and the optimal conditions to make it using 3D printing technology. In addition, TPU can be easily obtained in the market and, thus, was chosen for this study to enable not only an expert but anyone to create prototypes or customize personal protective equipment through $3 \mathrm{D}$ printing. The tensile strength, shock absorption, and compressibility properties were evaluated in relation to the conditions of printing (infill-the filling of the inside during printing-and specimen thickness). In addition, we analyzed the predictability of shock absorption (an important performance factor in personal protective equipment) with the analysis tool SolidWorks. Energy, displacement, and deformation were calculated using the elastic modulus, Poisson's ratio, and the shear factor of the $3 \mathrm{D}$ printed material, to propose an efficient model that can confirm the potential of a new material with regard to productivity, quality, and stability, without further experimentation. In addition, we tested prototype models on the human body (knee and crotch protectors) with different thickness and infill conditions, to confirm their applicability to actual use.

\section{Materials and Methods}

2.1. Samples and Output Conditions. TPU (HyVISION, South Korea) samples were 3D printed under different conditions to form test pieces for tensile, impact, and compressibility tests based on the appropriate standards (ISO 527-2 [22], ISO 6603-2 [23], and ISO 2039-2 [24], respectively). TPU filament type used for filling, detailed specifications are as follows: melt flow index $14-28 \mathrm{~g} /$ $10 \mathrm{~min}$, tensile yield strength $21-36 \mathrm{MPa}$, elongation at break 26-60\%, flexural strength $60-97 \mathrm{MPa}$, flexural modulus $1.8-3.0 \mathrm{GPa}$, impact strength $120 \mathrm{~kJ} / \mathrm{m}^{2}$, and filament diameter $1.75 \mathrm{~mm}( \pm 0.05 \mathrm{~mm})$. Specimens were modeled using Geomagic Design X software (3D Systems, USA). Each bit of data had sliced G-codes appropriate for $3 \mathrm{D}$ printing using Cubicreator 2.5 R3 software (HyVISION, South Korea), and the specimens were 3D printed using a Cubicon Style desktop 3D printer (HyVISION, South Korea) at a printing speed of $10 \mathrm{~mm} / \mathrm{s}$, floor temperature of $65^{\circ} \mathrm{C}$, chamber temperature of $50^{\circ} \mathrm{C}$, and discharge rod temperature of $230^{\circ} \mathrm{C}$. This printer is one of the most commonly used low-cost techniques in the field of $3 \mathrm{D}$ printing. The sample thickness and infill printing condition were varied ( 5 or $10 \mathrm{~mm}$ thickness; $10 \%, 50 \%$, or $100 \%$ infill), providing six types of samples. Four copies of each sample were made so that four trials could be performed for each evaluation category to derive the average and standard deviation. Detailed conditions of 3D printing are shown in Table 1 . The symbol of the sample was determined based on the thickness and infill condition, and the final name was determined based on the sample weight measurement value, which is shown in Table 2. The material consumption of the sample was $45.24 \mathrm{~g}$ for $10 \mathrm{~T} 100$, $27.69 \mathrm{~g}$ for $10 \mathrm{~T} 50,13.64 \mathrm{~g}$ for $10 \mathrm{~T} 10,22.65$ for $5 \mathrm{~T} 100$, $15.80 \mathrm{~g}$ for $5 \mathrm{~T} 50$, and $10.32 \mathrm{~g}$ for $5 \mathrm{~T} 10$. As a result of verifying the morphological properties of the output of TPU printing in the previous study [25], no particles were found in the smooth surface when $100 \%$ TPU was supplied, and the release kinetic was maintained at higher purity $(3.9 \pm 0.9 \%)$ in the X-ray tomography image. Based on the result of the previous study, this study also premised that porosity would not occur during the printing process. This assumption was addressed by utilizing the SEM images presented in Table 1 for examination, and only the percentage indicated by the weight measurement was considered. On the contrary, before printing, the function of leveling the bed was performed by auto leveling, and the sample was placed in a lower position of the $Z$-axis for the bottom surface to be horizontal. This minimized the effect of load during the output. In addition, when outputting protective equipment larger than the sample in this study, placing the wide surface of the modeling sample horizontally can provide a more stable $3 \mathrm{D}$ printing and is less likely to fail. 
TABLE 1: Detailed conditions of 3D printing.

\begin{tabular}{|c|c|c|c|c|c|c|c|c|}
\hline \multirow[b]{2}{*}{$10 \%(14 x)$} & \multicolumn{2}{|l|}{ Fill pattern } & \multicolumn{4}{|c|}{ Number of layers } & \multirow{2}{*}{$\begin{array}{l}\text { Overlap with outer wall } \\
(\%)\end{array}$} & \multirow{2}{*}{$\begin{array}{l}\text { Height of layer } \\
(\mathrm{mm})\end{array}$} \\
\hline & $50 \%(24 x)$ & $100 \%(24 \mathrm{x})$ & $5 \mathrm{~T}$ & $10 \mathrm{~T}$ & $\begin{array}{l}\text { Top } \\
\text { (ea) }\end{array}$ & $\begin{array}{c}\text { Bottom } \\
\text { (ea) }\end{array}$ & & \\
\hline & & & 25 & 50 & 6 & 3 & 15 & 0.2 \\
\hline
\end{tabular}

TABLE 2: Variables for experimental samples and properties tested.

\begin{tabular}{lcccc}
\hline & Thickness & Infill \\
\hline Condition & $5 \mathrm{~mm}$ & $10 \mathrm{~mm}$ & $10 \%$ & $50 \%$ \\
Naming & $5 \mathrm{~T}$ & $10 \mathrm{~T}$ & 10 & 50 \\
& & $5 \mathrm{~T} 10(p 45 \%), 5 \mathrm{~T} 50(p$ 70\%), 5T100 $(p 100 \%)$ \\
Sample names $(p \%$; porosity $\%)$ & & $10 \mathrm{~T} 10(p 30 \%), 10 \mathrm{~T} 50(p$ 61\%), $10 \mathrm{~T} 100(p 100 \%)$ \\
Property tested & & Tensile strength, shock absorption, and compressibility tests \\
\hline
\end{tabular}

\subsection{Property Analysis}

2.2.1. Tensile Testing. The tensile properties of the TPU samples were measured according to ISO 527-2 [22]. The test piece had $75 \mathrm{~mm}$ gauge marks, and the test was performed at a tensile velocity of $50 \mathrm{~mm} / \mathrm{min}$.

2.2.2. Impact Testing. Impact tests were carried out to analyze the shock absorption properties of the TPU specimens for application as personal protective equipment. The Roller Sports Protective Equipment [26] testing method from the Korea Products Safety Association was followed, which is a drop test commonly used in industry to determine the ability of a material to cushion impacts [27]. A shock striker with $12.7 \mathrm{~mm}$ diameter and $5 \mathrm{~kg}$ mass was dropped from a height of $10 \mathrm{~cm}$, applying a force of $50 \mathrm{~N}$. The maximum impact force and peak energy were measured. The shock absorption results were statistically analyzed with one-way ANOVA using SPSS 24.0 (IBM soft, USA). The posttest performed was the Duncan test.

2.2.3. Compression Testing. With reference to ISO 604 [28] for plastic compression testing, the compressibility was measured at a compressive velocity of $1 \mathrm{~mm} / \mathrm{in}$, using a $30,000 \mathrm{~N}$ rod cell and a $24,000 \mathrm{~N}$ proof load using a universal tester (WITHLAB, WL2100, South Korea).

Table 3 shows the modeled specimen shapes for each experiment. The temperature and the relative humidity for all experiments were $22 \pm 1^{\circ} \mathrm{C}$ and $(40.0 \pm 3) \%$, respectively.

The model produced for the experiment in this study was designed in compliance with the standard specification for property analysis. However, the thickness was generally $5.0 \sim 10.0 \mathrm{~mm}$, which is the thickness of the protective hard shell and the shock absorbing foam.
2.3. Structural Analysis. Using the SolidWorks 2016 program (Dassault Systèmes, South Korea), a structural analysis was performed for $3 \mathrm{D}$ models of the square TPU samples used for shock absorption and compression tests. For the analysis, the material's properties were provided by the SolidWorks program. TPU had the following properties: elastic modulus $2410 \mathrm{~N} / \mathrm{mm}^{2}$, Poisson's ratio 0.3897 , and shear factor $862.2 \mathrm{~N} / \mathrm{mm}^{2}$. A $12.7 \mathrm{~mm}$ diameter circle was drawn at the center of the surface of each model to set the area of the vertical load, to mimic the actual tests. The load on each sample was set to $50 \mathrm{~N}$, as in the shock absorption tests. After the analysis conditions were set, a mesh of the modeling data was created, and the simulation was executed. Figure 1 shows the modeling dimensions as well as the analysis conditions and procedure. The peak force, displacement, and deformation were then compared and analyzed to investigate the possibility of predicting shock absorption results by simulation. To compare the simulation and actual experimental results, the shape of the center of the $10 \mathrm{~T}$ samples deformed by the shock striker after the impact tests was observed, as depicted in Figure 2, using the SEM images and a three-dimensional scan coordinate measuring machine (CONTURA G2, ZEISS, Oberkochen, Germany).

\section{Results and Discussion}

3.1. Tensile Properties. It is often necessary to design protective equipment that will provide ample protection against hazards such as impact, penetration, and compression. The stress-strain graphs generated from tensile testing of the samples are given in Figure 3. Unlike regular fabrics, the TPU samples did not fracture because of their rubber-like traits. In general, fabrics are woven from fibers, whose strength of a fiber is defined as the force or tensile strength in the longitudinal direction divided by the fiber thickness. Using the g/d unit, silk, nylon, and polyester fibers were 
TABLE 3: 3D modeling specification.

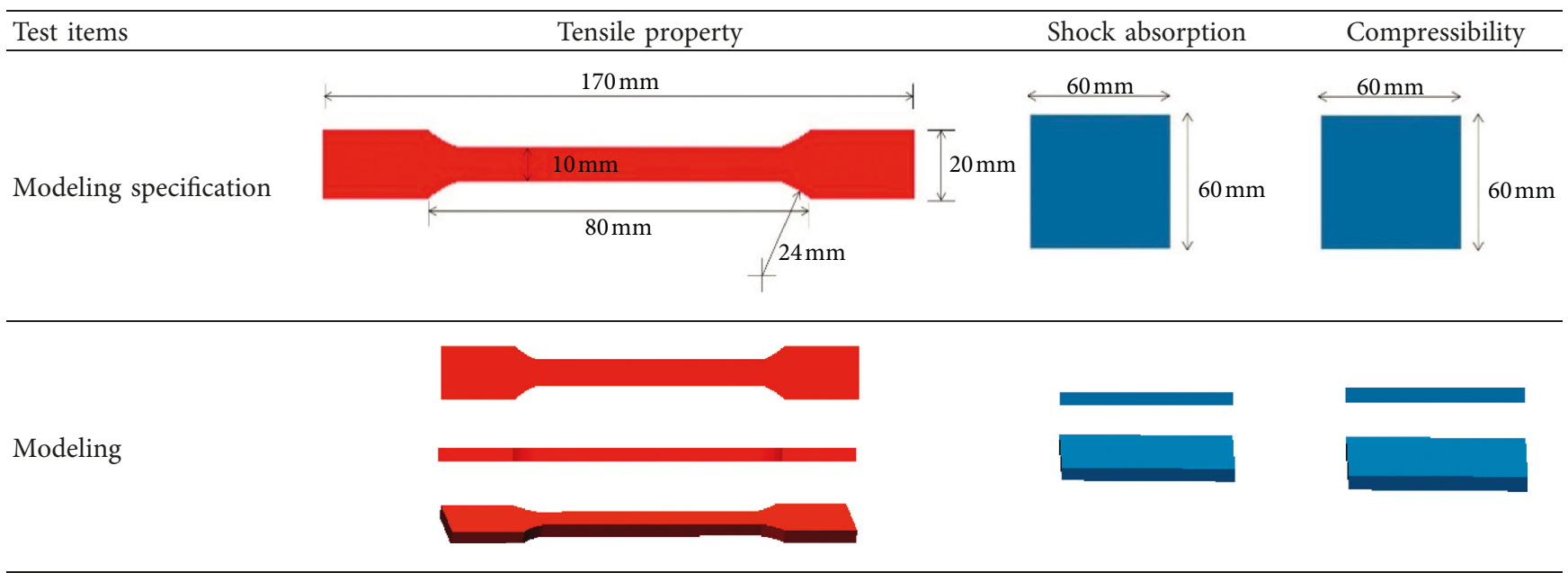

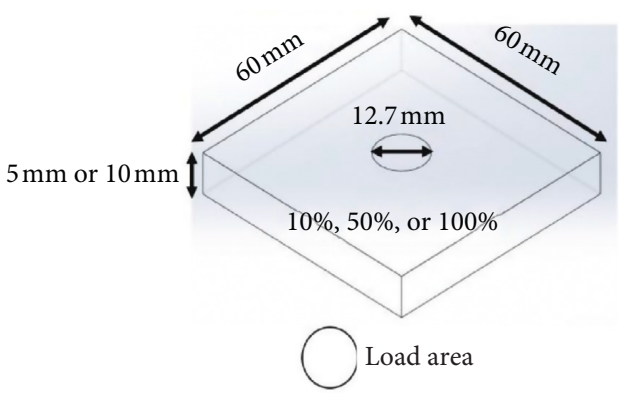

(a)

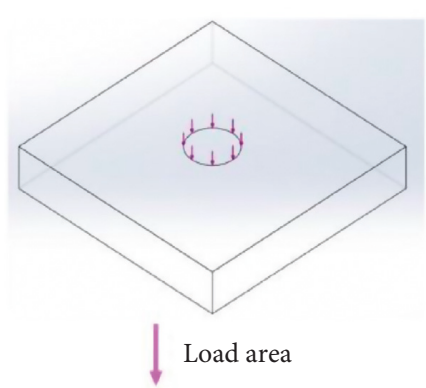

(b)

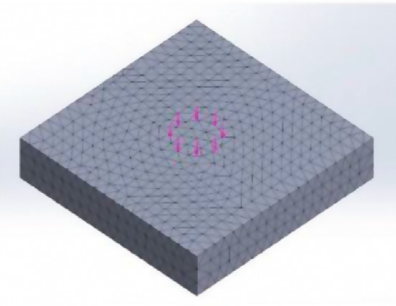

(c)

FIGURE 1: Location and dimensions of load area for the structural analysis. (a) Modeling. (b) Load value input. (c) Mesh creation.

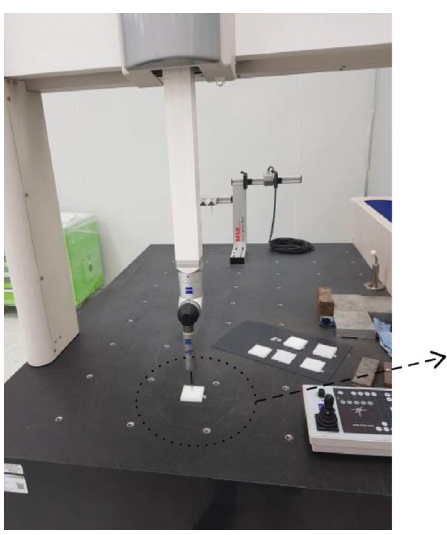

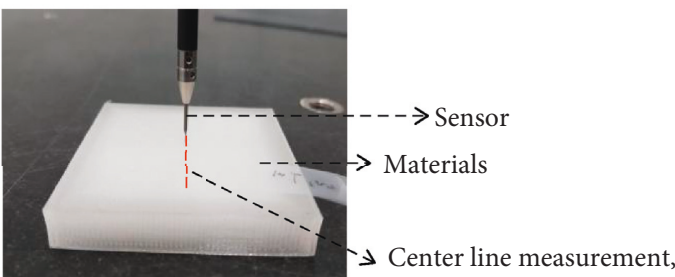

repeat 4 times

CONTURA G2

Figure 2: 3D coordinate scan method for results after impact testing.

found to have a tenacity of $>0.6 \mathrm{~g} / \mathrm{d}$, while cotton, rayon, flax, and acetate fibers had tenacities of $0.2 \mathrm{~g} / \mathrm{d}$ or less [29]. As the TPU fabric is printed directly (i.e., it is not made of woven fibers), the tensile strength is measured in $\mathrm{MPa}$, and the property is different from general fibers. An increase in the TPU infill rate led to an increase in stress, regardless of the sample thickness. This makes the infill ratio an important factor for determining the tensile strength. 


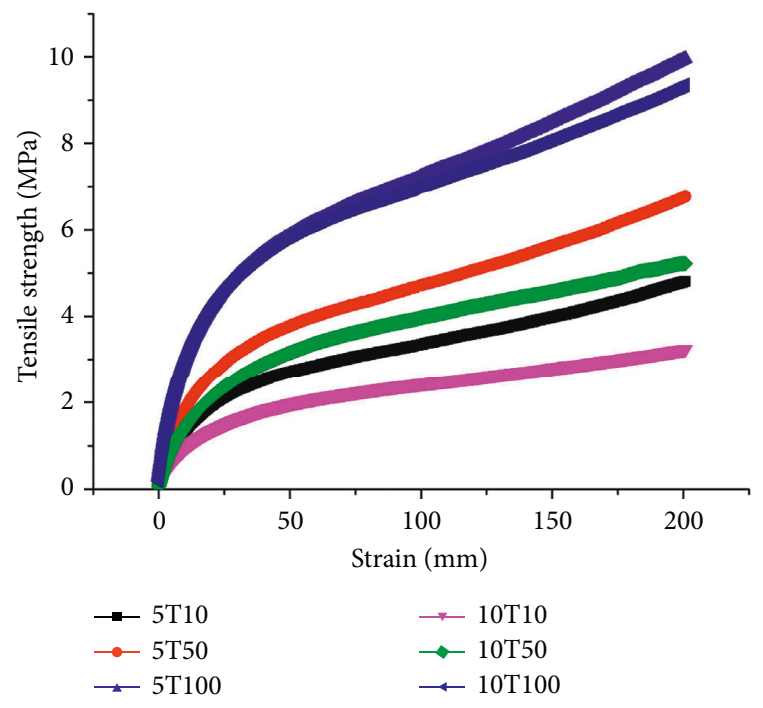

Figure 3: 5T10, 5T50, 5T100, 10T10, 10T50, and 10T100 stressstrain curves.

When viewing the initial modulus (i.e., the slope of the stress-strain curve close to the origin), there was no difference between the two thicknesses when the infill was $100 \%$, but a discrepancy was observed as the percentage of infill decreased, with the thinner samples having a lower initial modulus. In other words, the thicker samples stretched faster under a lower tensile stress at an infill of $10 \%$ or $50 \%$. Various plastic materials have tensile strengths ranging from 15.5 to $150 \mathrm{MPa}$ when measured using the ASTM D638 test method [30]. In addition, the properties of plastics can be altered through processing and mixing. For example, the stress to failure of pure PLA is $54.33 \mathrm{MPa}$ [31], but when TPU is added, the elongation rate increases, while the stress to failure decreases to approximately 20-24 MPa. Tymrak et al. [32] found that the average tensile strengths for ABS and PLA were 28.5 and $56.6 \mathrm{MPa}$, respectively, with average elastic moduli of 1807 and $3368 \mathrm{MPa}$, respectively. The addition of TPU, which is a rubbery material, increased flexibility but decreased hardness. The current results also show that, with $100 \%$ infill, the stress on the TPU sample was approximately $10 \mathrm{MPa}$ when stretched to $200 \mathrm{~mm}$, regardless of the thickness. Thus, its tensile strength was much lower than that of other plastic materials.

3.2. Shock Absorption Properties. The shock absorption capabilities of the TPU samples were evaluated in relation to the thickness and infill conditions, with the results depicted in Figure 4. Table 4 shows the peak force $(\mathrm{N})$ and total absorbed energy ( $\mathrm{J}$ ) on impact. The peak force value increased as the infill ratio increased for samples of the same thickness. At $100 \%$ infill, the peak force increased with thickness $(p<0.001)$, with the 5 and $10 \mathrm{~mm}$ samples $(100 \%$ infill) having peak forces of 938.1 and $1325.3 \mathrm{~N}$, respectively-an increase of $380 \mathrm{~N}$. In contrast, the peak force was not heavily affected by the thickness when the infill ratio was $10 \%$ or $50 \%$.

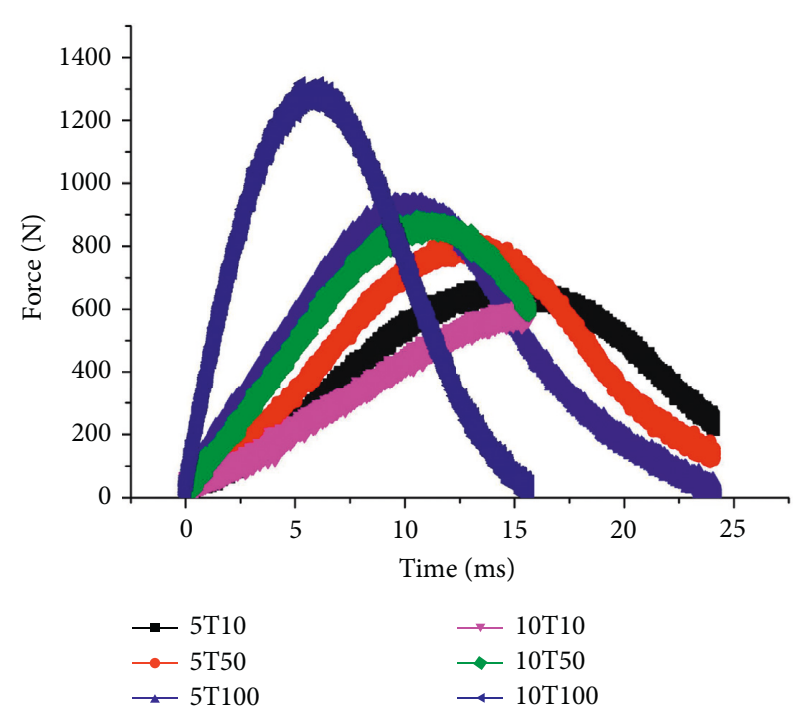

Figure 4: 5T10, 5T50, 5T100, 10T10, 10T50, and 10T100 shock absorption in relation to the printing conditions.

TABle 4: Peak force and total energy of absorption.

\begin{tabular}{lcc}
\hline Sample & $\begin{array}{c}\text { Peak force (N) } \\
\text { Mean (S.D.) }\end{array}$ & $\begin{array}{c}\text { Total energy (J) } \\
\text { Mean (S.D.) }\end{array}$ \\
\hline 5T10 & $690.9(6.09)$ & $5.8(0.07)$ \\
5T50 & $832.8(7.03)$ & $4.5(0.04)$ \\
5T100 & $938.1(7.03)$ & $4.0(0.06)$ \\
$10 \mathrm{~T} 10$ & $626.9(5.80)$ & $5.7(0.01)$ \\
10T50 & $894.8(1.32)$ & $5.1(0.04)$ \\
10T100 & $1325.3(8.45)$ & $4.5(0.04)$ \\
\hline
\end{tabular}

The total energy tended to decrease with increasing infill $(p<0.001) .10 \mathrm{~T} 10$ and 5T10 samples with low $p \%$ showed the highest energy absorption, but all the samples absorbed most of the $5 \mathrm{~J}$ initial load with no fractures. Therefore, this indicates that their cushioning abilities were similar. However, among them, the $100 \%$ infill samples can be interpreted as having better resistance to impact force, owing to their high peak force. This supports the polynomial function proposed in Verstraete's study [25], wherein the internal lattice structure of a printed sample is compressed at the same strain rate; however, high porosity is likely to cause the material deformation:

$$
\begin{aligned}
& F \propto\left(1-\varnothing_{g}\right)^{3}, \\
& \varnothing_{g}=1-\frac{\rho}{\rho_{s}},
\end{aligned}
$$

where $\rho$ and $\rho_{s}$ are densities.

As shown by equation (1), the peak force decreases with increasing porosity, and the energy absorption is inversely correlated with $p \%$. The materials used for personal equipment to protect the body from impact are mainly rubber, aluminum, steel, fiber, or plastic [33]. Among these materials, plastics and foams are frequently used for protective equipment in our daily lives but rarely as personal 
protective equipment in industrial uses [20]. In previous studies $[4,6]$, the absorption rate of impact energy was evaluated in relation to the thickness of the plastic; it was concluded that thickness is a highly influential factor. Although greater thickness meant a lower impact absorption rate considering the increase in weight, the optimal conditions for the human body still had to be investigated. In other words, even if the impact absorption rate is maximal, if it requires more weight to be applied to the body, discomfort and thermal stress may occur, leading to ineffective protection. However, in this study, it was found that 3D printed TPU equipment that can protect against peak forces of less than $800 \mathrm{~N}$ could be thin (light) and still have a high shock absorption rate. However, if more than $1000 \mathrm{~N}$ of peak force had to be absorbed, the thickness would be a highly significant factor.

3.3. Compressibility Properties. Figure 5 shows the results of compressive testing on samples with different thicknesses for each of the infill conditions. The compressive strength showed large changes according to the infill ratio, similar to the tensile and shock absorption properties. Relative analysis of the energy required to compress each sample to a certain load showed that the compression energies of both the 5 and $10 \mathrm{~mm}$ thick samples increased as the infill ratio increased. The compression energy also increased as the thickness decreased under identical infill conditions. Clear inflection points were observed in the compression energy-strain graphs for samples with $10 \%$ and $50 \%$ infill but not for those with $100 \%$ infill, regardless of the thickness. For the samples with $10 \%$ infill, the compression energy quickly increased for the first $1.0 \mathrm{~mm}$ of strain, with an inflection point observed at approximately $1.0 \mathrm{~mm}$. On the contrary, the samples with $50 \%$ infill initially compressed linearly and displayed an inflection point at approximately $1.5 \mathrm{~mm}$ strain. However, the samples with $100 \%$ infill compressed almost linearly throughout the whole test.

Despite these differences, all the samples were capable of retaining their shape for a certain amount of time after the maximum compressive stress was reached, rather than showing a sudden decrease in strength or fracturing. Moreover, the gradual increase of pressure near the deformation point upon initial compression demonstrates that the material provided soft cushioning. This is likely to be related to TPU's characteristic flexibility. For equipment that requires better protection from compression, the infill condition should be set to $100 \%$. Furthermore, as changing the thickness does not considerably change the compressive properties, using thinner equipment may be beneficial when considering weight. With comprehensive assessment of the shock absorption results, it is necessary to find the optimal processing conditions to bestow a particular piece of protective equipment with the required properties.

3.4. Structural Analysis. For the structural analysis, the material's properties were provided by the SolidWorks program and the tensile strength was input as the average tensile strength of each specimen from the experimental analyses. The elastic modulus was obtained from equation (2), based on the measured tensile strengths [34] (5T10: $0.1935 \mathrm{~N} / \mathrm{m}^{2}$; 5T50: $0.2819 \mathrm{~N} / \mathrm{m}^{2}$; 5T100: $0.4656 \mathrm{~N} / \mathrm{m}^{2}$; 10T10: $0.1470 \mathrm{~N} / \mathrm{m}^{2}$; 10T50: $0.2214 \mathrm{~N} / \mathrm{m}^{2}$; and $10 \mathrm{~T} 100$ : $0.4658 \mathrm{~N} / \mathrm{m}^{2}$ ), where $E$ is Young's modulus $(\mathrm{Pa}), \sigma$ is the uniaxial stress or uniaxial force per unit surface $(\mathrm{Pa})$, and $\varepsilon$ is the strain or proportional deformation. In practice, Young's modulus is given in megapascals ( $\mathrm{MPa}$ or $\left.\mathrm{N} / \mathrm{mm}^{2}\right)$ :

$$
E=\frac{\sigma}{\varepsilon}
$$

Table 5 shows the structural analysis of each model. Here, the energy is calculated from the force $(\mathrm{N})$ and displacement $(\mathrm{m})$ by the following equation, where the force was calculated by multiplying pressure $(\mathrm{Pa})$ and area of circle for vertical load $\left(\mathrm{m}^{2}\right)$ :

$$
\begin{aligned}
\text { energy of absorption }(\mathrm{J})= & {\left[\text { pressure }(\mathrm{Pa}) \times \text { unit area }\left(\mathrm{m}^{2}\right)\right] } \\
& \times \text { displacement }(\mathrm{m}) \\
= & \text { force }(\mathrm{N}) \times \text { displacement }(\mathrm{m}) .
\end{aligned}
$$

The energy level decreased as the percentage infill increased. However, the thicker samples had greater peak force. This tendency is similar to the data from actual measurements in Table 4, suggesting that it can be predicted using structural analysis. Nevertheless, a correction coefficient is required to ensure the actual measurement data completely match the calculated values, and further research is needed. Based on this result, an image of the displacement during shock absorption is shown in Figure 6. In this figure, 10T10 and 10T50 have the stress focused at the center, where the load is applied, suggesting the possibility of plastic deformation when a physical load is applied. Figure 7 shows the result of scanning the shape of the sample after actual impact testing through 3D coordinate scan analysis and SEM images for 10T10, 10T50, and 10T100 samples. It was difficult to distinguish the samples based on the SEM images; that is, the amount pressed by the impact was found to be very small. Therefore, it can be interpreted that these samples are suitable as a protective material in terms of wearing durability and aesthetics. However, an additional 3D coordinate scan analysis was performed to quantitatively observe the differences between each sample. $10 \mathrm{~T} 10$ was the largest deformation of $-0.1222 \mathrm{~mm}$. 10T50 and $10 \mathrm{~T} 100$ were $-0.05223 \mathrm{~mm}$ and $-0.05083 \mathrm{~mm}$, respectively, and the difference between the two samples was insignificant. $10 \mathrm{~T} 10$ showed similar analysis and experimental values, and the lower the filling ratio, the greater the deformation caused by impact. In terms of deformation, fill rates $50 \%$ ( $p$ 60 70\%) and 100\% ( $p$ 100\%) are expected to be favorable and exhibit the desired even stress distribution and low deformation for crafting protective equipment. On the contrary, since output with 10\% ( $p$ 30 40\%) is high in flexibility and energy absorption, it can be considered as a protective device for clothing that is not exposed to very strong impacts. 


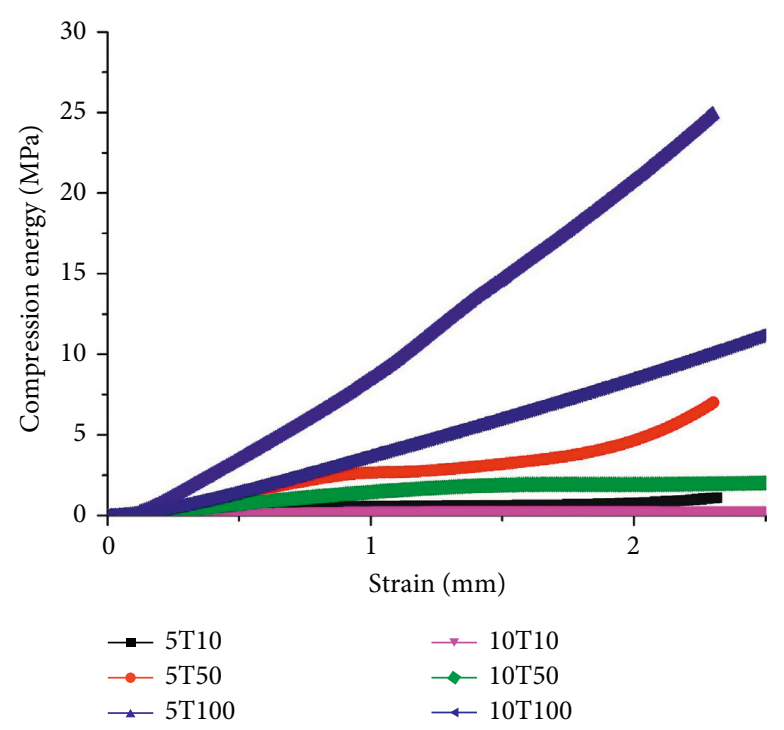

(a)

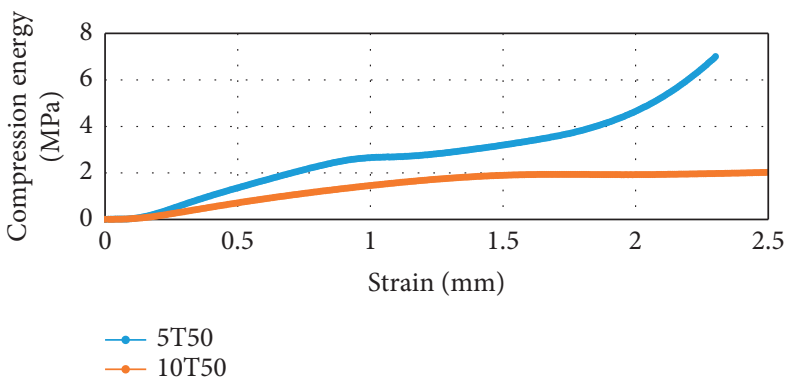

(c)

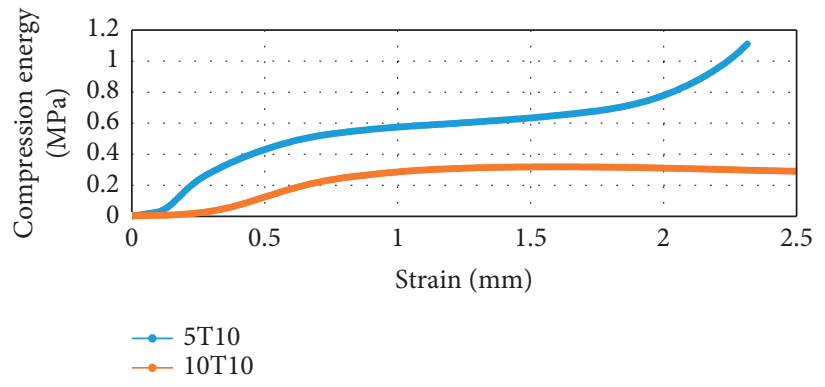

(b)

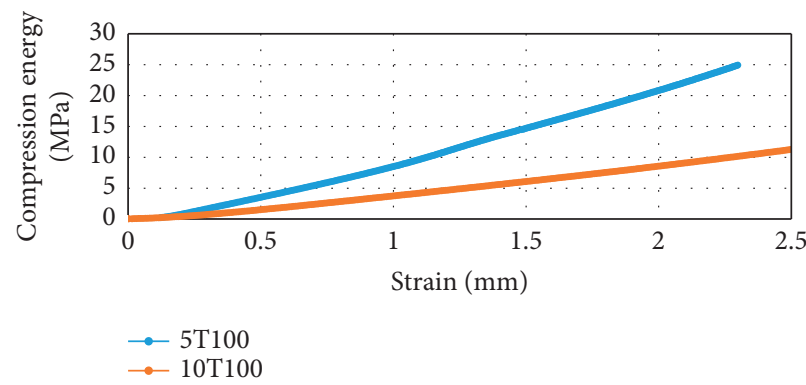

(d)

Figure 5: Compressibility property in relation to thickness with $10 \%, 50 \%$, and $100 \%$ infill rates.

TABLE 5: Structural analysis results of absorption energy.

\begin{tabular}{lc}
\hline Sample & Energy $(\mathrm{kJ})$ \\
\hline 5T10 & 2.3 \\
5T50 & 1.6 \\
5T100 & 1.0 \\
10T10 & 6.3 \\
10T50 & 4.1 \\
10T100 & 1.9 \\
\hline
\end{tabular}

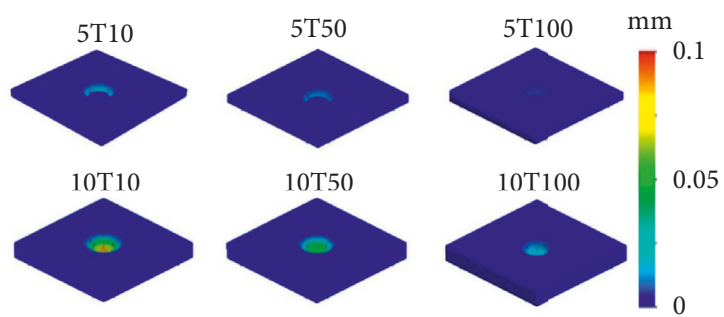

Figure 6: 3D simulation of displacement.

3.5. Application for Protective Gear. The results of this study demonstrate that, for moderate protective gear (i.e., absorbs $<1000 \mathrm{~N}$ impact energy and protects from weak compression), the higher the infill condition, the higher the strength, but the lower the flexibility. Therefore, we modeled various crotch [35] and knee protectors [36] to be worn on the human body to demonstrate the potential applications. Table 6 shows the modeling and output of the crotch and knee protectors. We also investigated whether the product is practical to use when $3 \mathrm{D}$ printing with $10 \%$ infill and $5 \mathrm{~mm}$ thickness. The reason for this is that the thickness of the form of the crotch or knee protective gear is generally sold in the market in the range of $5-10 \mathrm{~mm}$, and the consumer complaints regarding the current products include lack of flexibility and less comfort when worn. The production of samples was printed to examine the applicability of the results of this study, and $10 \%$ infill condition was found to have suitable comfort for wearing, owing to its moderate flexibility.

In future studies, more complex samples will be developed and evaluated for stability as well as subject's wear comfort. When evaluating the impact and energy absorption, it is expected that if the evaluation is performed not only on a plane but also on various areas of the complex curved surface, then it will be possible to obtain a highly practical application result. 


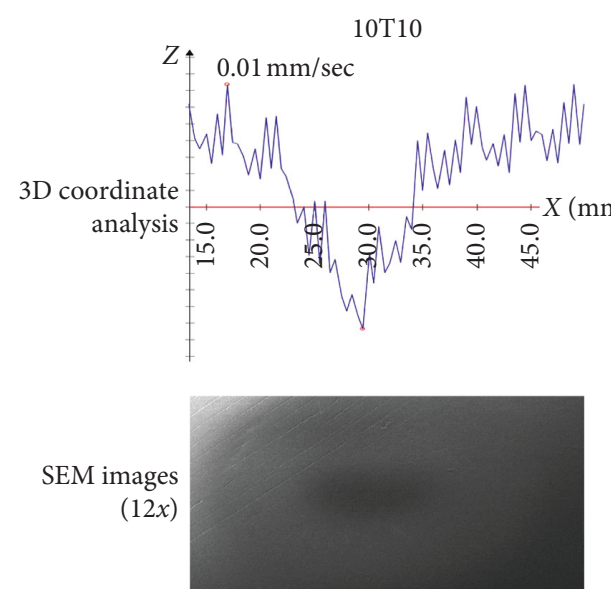

(a)
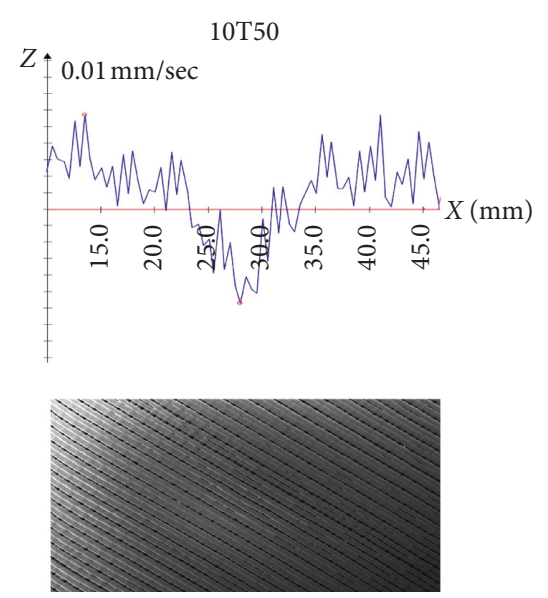

(b)
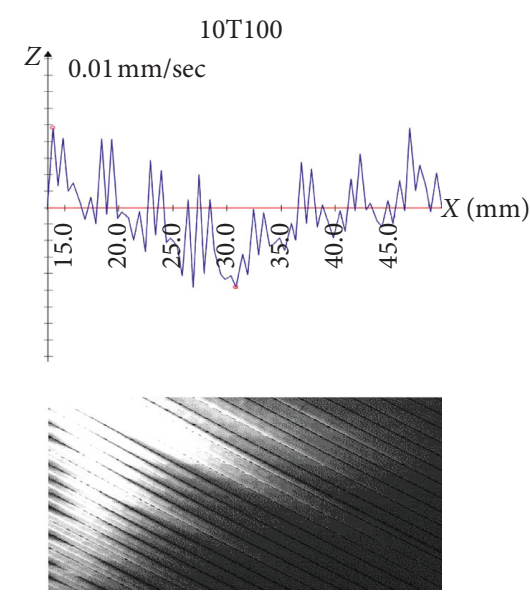

(c)

FIgURE 7: 3D coordinate analysis and SEM photos of shock absorption after impact testing. (a) 10T10. (b) 10T50. (c) 10T100.

TABLE 6: Modeling and printout of crotch and knee protectors as example applications.

3D modeling

Crotch protector for cycling

$3 \mathrm{D}$ printing

3D modeling

Knee protector for sports activity
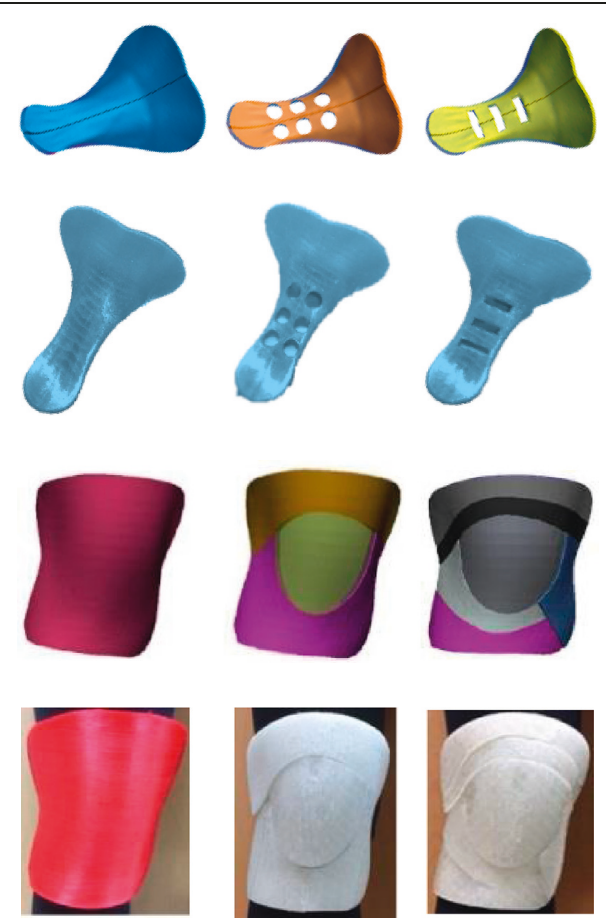

\section{Conclusions}

Overall, TPU does not fracture like regular fiber. Its strength is proportional to the infill rate during printing, regardless of the sample thickness, making the infill rate an important factor in determining the strength of the resultant material. The maximum impact values also increased as the infill increased when samples of identical thicknesses were compared. However, although the peak force was not heavily affected by the thickness when the infill rate was $10 \%$ or $50 \%$, the greater thickness greatly assisted shock absorption when the infill rate was $100 \%$. Therefore, when the impact absorption conditions are below $800 \mathrm{~N}$, the thickness is insignificant, so it is beneficial to use a thin material that lowers the weight and retains high shock absorption. However, when absorbing over $1000 \mathrm{~N}$ of shock energy, the thickness becomes a key factor. All the specimens absorbed a total energy of at least $5 \mathrm{~J}$. Therefore, it was confirmed that TPU material created using 3D printing could be used as personal protective equipment. The compression energy also 
increased as the infill rate increased, regardless of the thickness. The increase was more drastic when the infill rate was $100 \%$ than for $10 \%$ or $50 \%$. If the part was required to protect from high compression, the infill rate needed to be $100 \%$. Thin materials should also be chosen when weight is a consideration because the thickness was relatively insignificant. Structural analyses showed that the thinner the material, the less deformation was caused by the impact, regardless of the infill condition. In addition, it was confirmed that the same tendency as the experimental results of the actual impact testing was shown. In the future, experiments are expected to be performed by simulating the properties of new materials, as well as different thickness and infill conditions. Thus, when 3D printing the TPU material over the hard shell of protective equipment, the infill condition must be set to $100 \%$ to achieve the desired shock absorption and compression properties. However, the thickness must be set considering the importance of the protective function. Moreover, the tensile strength was much lower than general plastic even when the infill condition was $100 \%$. Hence, it should be very comfortable to wear because of the low level of constraint on the body. However, it will be advantageous to apply reinforced plastic instead of TPU if extreme protection is required; in which case, a morphologic approach for comfort, such as structural incisions or holes, will be necessary. Therefore, selecting the optimal conditions and conducting modeling to precisely determine the desired protective conditions are considered very important. We examined the effectiveness of the sample with $10 \%$ infill and $5 \mathrm{~mm}$ thickness in two example applications (crotch protector and knee protector), which are worn on the human body. It was found that the product was suitable in terms of wearing comfort, stability, and flexibility.

Although this study was restricted to the use of TPU, further studies will be conducted with the addition of newly developed materials to produce a continuously developed database. This can be applied as a fundamental basis for developing protective materials. Actual protective devices could also be produced to conduct wearing tests.

\section{Data Availability}

The data used to support the findings of this study are included within the article.

\section{Conflicts of Interest}

The authors declare that they have no conflicts of interest.

\section{Acknowledgments}

This work was supported by the National Research Foundation of Korea (NRF) grant funded by the Korea Government (MSIT) (no. 2016-1956).

\section{References}

[1] J. C. Glenn, T. J. Gordon, and E. Florescu, State of the Future, The Millennium Project, Washington, DC, USA, 2014.
[2] International Organization for Standardization, Additive Manufacturing-General Principles-Terminology, ISO/ ASTM 52900, Geneva, Switzerland, 2015.

[3] H. Lee, "A study of the production of textiles using 3D printing technology," Master's Degree, Hanyang University, Seoul, Republic of Korea, 2017.

[4] N. G. Tanikella, B. Wittbrodt, and J. M. Pearce, "Tensile strength of commercial polymer materials for fused filament fabrication 3D printing," Additive Manufacturing, vol. 15, pp. 40-47, 2017.

[5] H. S. Kim and I. A. Kang, "Study on status of utilizing 3D printing in fashion field," Journal of the Korea Fashion and Costume Design Association, vol. 17, no. 2, pp. 125-143, 2015.

[6] F. S. Senatov, K. V. Niaza, M. Y. Zadorozhnyy, A. V. Maksimkin, S. D. Kaloshkin, and Y. Z. Estrin, "Mechanical properties and shape memory effect of 3Dprinted PLA-based porous scaffolds," Journal of the Mechanical Behavior of Biomedical Materials, vol. 57, pp. 139-148, 2016.

[7] E. Mikołajewska, M. Macko, Ł. Ziarnecki et al., "3D printing technologies in rehabilitation engineering," Health Science Journal, vol. 4, no. 12, pp. 78-83, 2014.

[8] J. W. Stansbury and M. J. Idacavage, "3D printing with polymers: challenges among expanding options and opportunities," Dental Materials, vol. 32, no. 1, pp. 54-64, 2016.

[9] F. Shen, S. Yuan, Y. Guo et al., "Energy absorption of thermoplastic polyurethane lattice structures via 3D printing: modeling and prediction," International Journal of Applied Mechanics, vol. 8, no. 7, 2016.

[10] S. R. Bates, I. R. Farrow, and R. S. Trask, "3D printed elastic honeycombs with graded density for tailorable energy absorption," in Active and Passive Smart Structures and Integrated Systems, vol. 9799, International Society for Optics and Photonics, Washington, DC, USA, 2016.

[11] S. R. G. Bates, I. R. Farrow, and R. S. Trask, "3D printed polyurethane honeycombs for repeated tailored energy absorption," Materials \& Design, vol. 112, pp. 172-183, 2016.

[12] J.-Y. Lee, J. An, and C. K. Chua, "Fundamentals and applications of 3D printing for novel materials," Applied Materials Today, vol. 7, pp. 120-133, 2017.

[13] B. C. Gross, J. L. Erkal, S. Y. Lockwood, C. Chen, and D. M. Spence, "Evaluation of 3D printing and its potential impact on biotechnology and the chemical sciences," Analytical Chemistry, vol. 86, no. 7, pp. 3240-3253, 2014.

[14] J.-F. Xing, M.-L. Zheng, and X.-M. Duan, "Two-photon polymerization microfabrication of hydrogels: an advanced 3D printing technology for tissue engineering and drug delivery," Chemical Society Reviews, vol. 44, no. 15, pp. 5031-5039, 2015.

[15] T. Hentschel and H. Münstedt, "Thermoplastic polyurethane-the material used for the erlanger silver catheter," Infection, vol. 27, no. 1, pp. S43-S45, 1999.

[16] A. Burke and N. Hasirci, "Polyurethanes in biomedical applications," Biomaterials, vol. 553, pp. 83-101, 2004.

[17] H.-Y. Mi, M. R. Salick, X. Jing et al., "Characterization of thermoplastic polyurethane/polylactic acid (TPU/PLA) tissue engineering scaffolds fabricated by microcellular injection molding," Materials Science and Engineering: $C$, vol. 33, no. 8, pp. 4767-4776, 2013.

[18] Y. Han and J. Kim, "A study on the mechanical properties of knit fabric using 3D printing-Focused on PLA, TPU Filament," Journal of Fashion Bus, vol. 22, no. 4, pp. 93-105, 2018. 
[19] S. H. Jang, T. H. Oh, and S. H. Kim, "Effects of heat treatment temperature on various properties of thermoplastic polyurethane composite fabrics," Textile Science and Engineering, vol. 54, no. 1, pp. 22-27, 2017.

[20] J.-H. Kim and G.-H. Kim, "Thermoplastic polyurethane (TPU)/ethylene-propylene-diene monomer rubber (EPDM) and TPU/polybutadiene rubber (BR) blends for the application of footwear outsole materials," Elastomers and Composites, vol. 48, no. 3, pp. 195-200, 2013.

[21] Y. Han and J. Kim, "Study on peel strength measurement of 3D printing composite fabric by using FDM," Journal of Fashion Bus, vol. 23, no. 2, pp. 77-88, 2019.

[22] International Organization for Standardization, Plastics-Determination of Tensile Properties-Part 2: Test Conditions for Moulding and Extrusion Plastics, ISO 527-2:2012, Geneva, Switzerland, 2017.

[23] European Standard, Plastics-Determination of Puncture Impact Behaviour of Rigid Plastics-Part 2: Instrumented Impact Testing, ISO 6603-2:2000, Europe, 2002.

[24] International Organization for Standardization, Plastics-Determination of Hardness-Part 2: Rockwell Hardness, ISO 2039-2:1987, Geneva, Switzerland, 2015.

[25] G. Verstraete, A. Samaro, W. Grymonpré et al., "3D printing of high drug loaded dosage forms using thermoplastic polyurethanes," International Journal of Pharmaceutics, vol. 536, no. 1, pp. 318-325, 2018.

[26] Korean Agency for Technology and Standards, Shock Absorption Performance Test Method, Korea Department of Ministry of Knowledge Economy, Sejong City, Republic of Korea, 2009.

[27] R. M. Silva, J. L. Rodrigues, V. V. Pinto, M. J. Ferreira, R. Russo, and C. M. Pereira, "Evaluation of shock absorption properties of rubber materials regarding footwear applications," Polymer Testing, vol. 28, no. 6, pp. 642-647, 2009.

[28] International Organization for Standardization, Plastics-Determination of Compressive Properties, ISO 604, Geneva, Switzerland, 2002.

[29] S. Kim, Cloth Materials, Gyeonggi-do: GyoMoon Publishers, Gyeonggi-do, Republic of Korea, 2000.

[30] K. Van de Velde and P. Kiekens, "Biopolymers: overview of several properties and consequences on their applications," Polymer Testing, vol. 21, no. 4, pp. 433-442, 2002.

[31] E. S. Park, "Thermal, mechanical and rheological properties of poly(lactic)acid/thermoplastic poly(ester)urethane/ $\mathrm{CaCO}_{3}$ composites," Master's Thesis, Hanyang University, Seoul, Republic of Korea, 2009.

[32] B. M. Tymrak, M. Kreiger, and J. M. Pearce, "Mechanical properties of components fabricated with open-source 3-D printers under realistic environmental conditions," Materials \& Design, vol. 58, pp. 242-246, 2014.

[33] P. G. Georgopoulos, P. Fedele, P. Shade et al., "Hospital response to chemical terrorism: personal protective equipment, training, and operations planning," American Journal of Industrial Medicine, vol. 46, no. 5, pp. 432-445, 2004.

[34] IUPAC, Compendium of Chemical Terminology, Blackwell Science, Oxford, UK, 1997.

[35] S. Park, H. Lee, and Y. Lee, "Suggestion of crotch prototype for cyclewear based on 3D modeling and printing," Journal of Human Ecology, vol. 28, no. 2, pp. 67-80, 2019.

[36] H. Lee and Y. Lee, "Segmental hard shell design of knee protector for children using 3D printing," Journal of Fashion Bus, vol. 21, no. 4, pp. 116-126, 2017. 


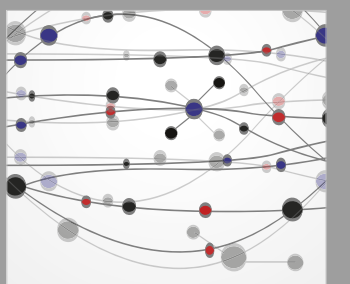

The Scientific World Journal
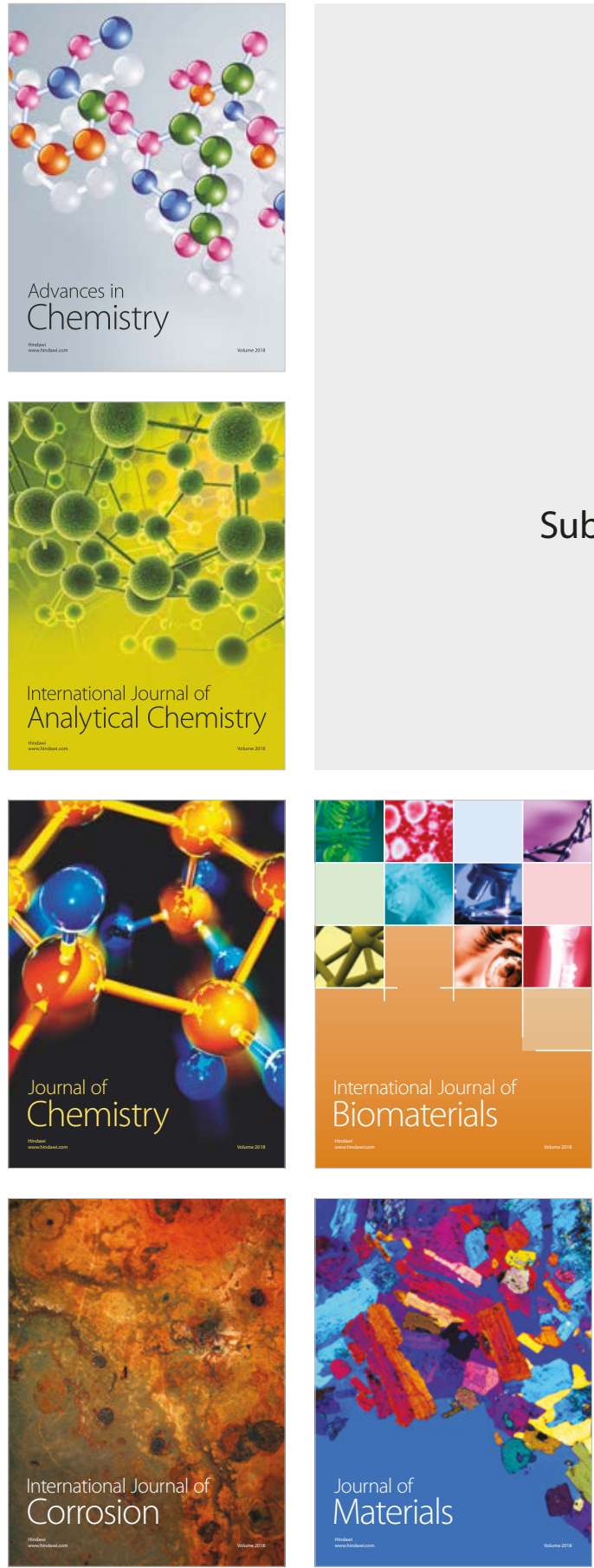

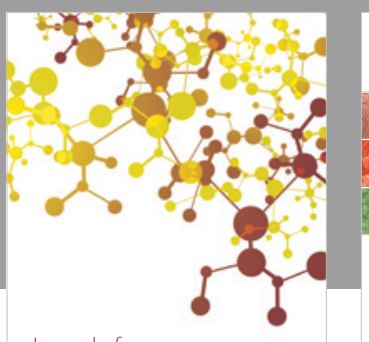

Journal of

Applied Chemistry
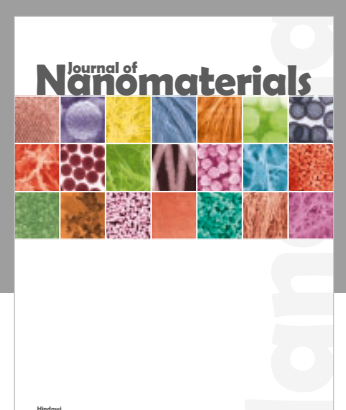

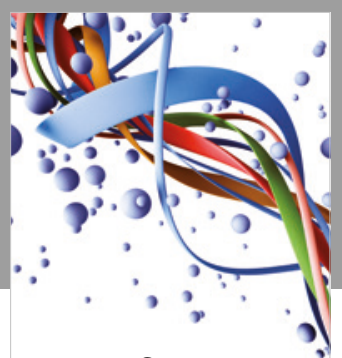

Scientifica

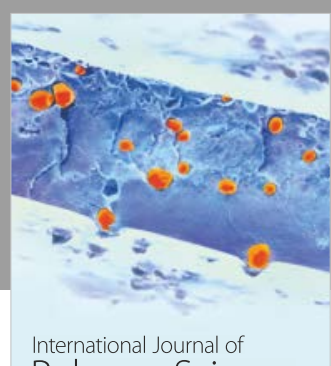

Polymer Science

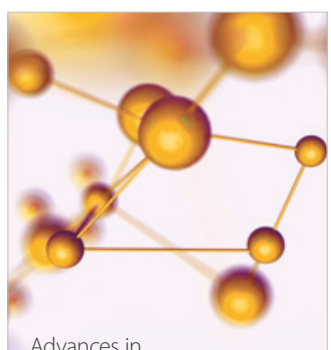

Physical Chemistry
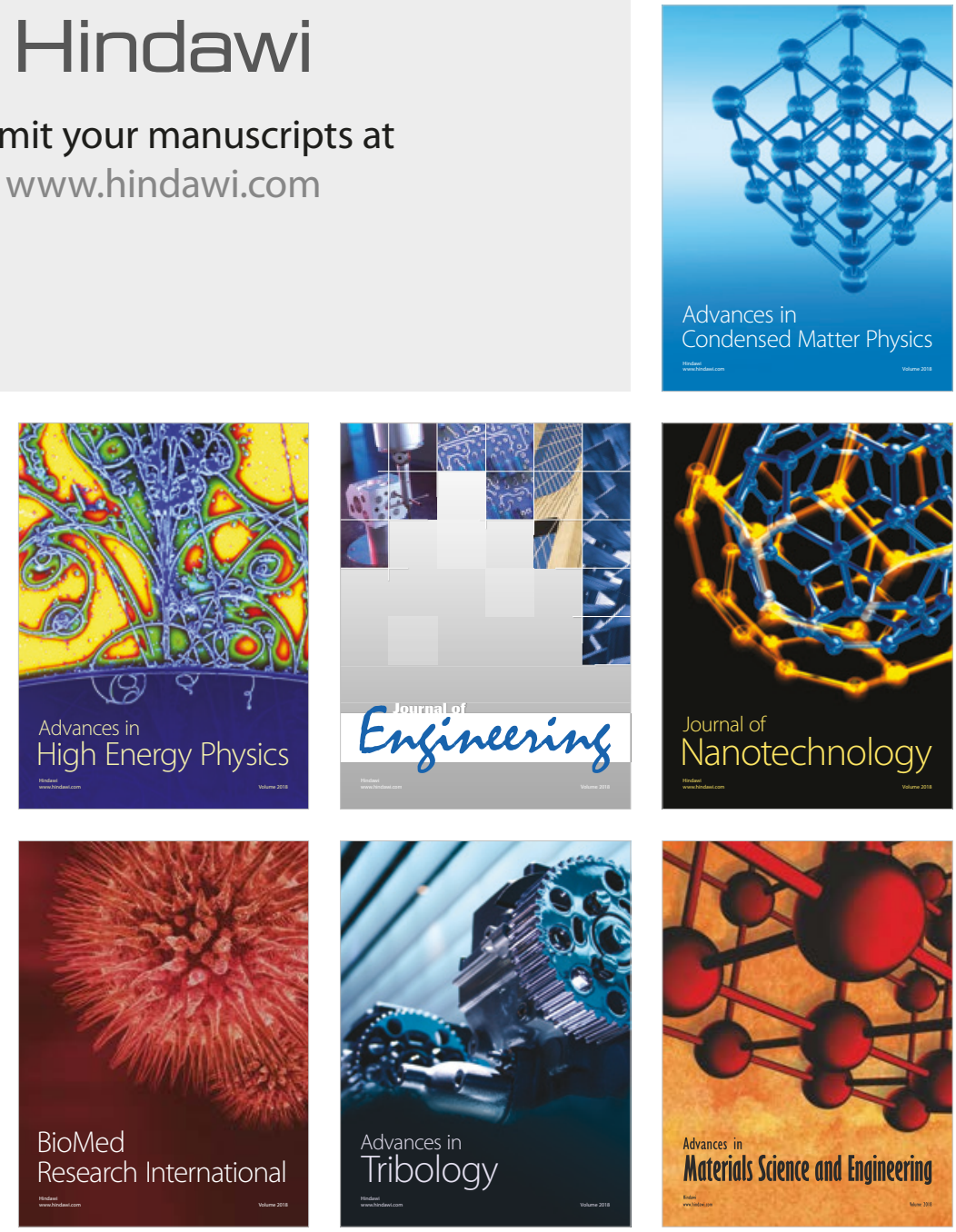